Check for updates

Cite this: RSC Adv., 2017, 7, 45185

\title{
Synthesis of carbon nanofibers by thermal conversion of the molecular precursor 5,6;11,12-di- 0 -phenylenetetracene and its application in a chemiresistive gas sensor $\dagger$
}

\author{
P. Krauß, T. Wombacher (D) and J. J. Schneider (D) *
}

Carbon nanofibers with an amorphous solid structure have been synthesized by thermal conversion of the polycyclic aromatic hydrocarbon 5,6;11,12-di-o-phenylenetetracene (DOPT) at $1000{ }^{\circ} \mathrm{C}$ on various substrates. Rapid annealing of DOPT on copper foil, $\mathrm{SiO}_{2} / \mathrm{Si}$ wafer and a $\mathrm{SiO}_{2} / \mathrm{Si}$ wafer coated with a $20 \mathrm{~nm}$ thick layer of Pt/Pd resulted in growth of carbon nanofibers. The most effective synthesis of these fibers was realized on the latter substrate. The Pt/Pd layer segregates by dewetting under thermal treatment and forms metallic nanoparticles on which dense networks of amorphous carbon nanofibers were prepared and these were successfully applied in chemiresistor gas sensor applications for detection of toxic gases, e.g. nitrogen dioxide, ammonia and sulfur dioxide. Using an analyte concentration of parts per million, the nanofibers show a very good response towards $\mathrm{NO}_{2}$ and $\mathrm{SO}_{2}$, whereas exposure to ammonia resulted only in negligible, minor changes in the electrical resistance of the sensor.

Received 26th July 2017

Accepted 12th September 2017

DOI: $10.1039 / \mathrm{c} 7 \mathrm{ra0} 8257 f$

rsc.li/rsc-advances

reactions leading to such oligomeric structures from PAHs involve C-C coupling reactions which are subsequently followed by cyclodehydrogenation type reactions generating finally the all carbon framework. ${ }^{12,17,18}$ For example a fusion of coronene $1^{13,16}$ or of the linear PAH pentacene $2^{12,16}$ is possible at temperatures as low as $400-800{ }^{\circ} \mathrm{C}$ in vacuum. Even the synthesis of highly defective graphene on copper substrates was demonstrated. It was shown that the control of defects by the choice of suitable precursors is possible. ${ }^{15}$ Moreover, carbon nanotubes have been synthesized using PAHs like xylene and pyrene as precursors in an arc discharge process. ${ }^{21}$

Herein, we demonstrate synthesis, characterization and sensoric behaviour of carbon nanofibers with an amorphous structure (a-CNFs) by thermal conversion of the recently available cross conjugated tetracene molecule 5,6;11,12-di-ophenylenetetracene (DOPT, 3). ${ }^{22,23}$ The obtained a-CNFs were studied towards their functional properties in a chemiresistor device for the detection of toxic gases. For this, nitrogen dioxide, ammonia and sulfur dioxide were chosen as analyte gases. These are environmentally hazardous and there is need to detect those gases even in smallest concentrations. Our interest in that area stems from the fact that carbon based nanomaterials, e.g. CNTs, ${ }^{24-26} \mathrm{CNFs}^{27-30}$ and graphene ${ }^{31,32}$ have proven to be effective alternatives to well-established metal oxide based gas sensors. Key features of these materials compared to metal oxides are operating temperatures as low as room temperature and an increased sensitivity and high versatility introduced by the ease of functionalization of these materials. ${ }^{33}$ Although a functionalized monolayer of graphene
Eduard-Zintl-Institut für Anorganische und Physikalische Chemie, Technische Universität Darmstadt, Alarich-Weiss-Straße 12, 64287 Darmstadt, Germany. E-mail: joerg.schneider@ac.chemie.tu-darmstadt.de

$\dagger$ Electronic supplementary information (ESI) available. See DOI: $10.1039 / \mathrm{c} 7 \mathrm{ra0} 257 \mathrm{f}$ 
a)<smiles>CC(C)(C)C(I)I</smiles>

Coronene<smiles>CC=CCC(C)=C(C)C</smiles>

b)<smiles>CC(C)(C)C(C)(C)C</smiles>

Cyclodehydrogenation

Cyclodehydrogenation

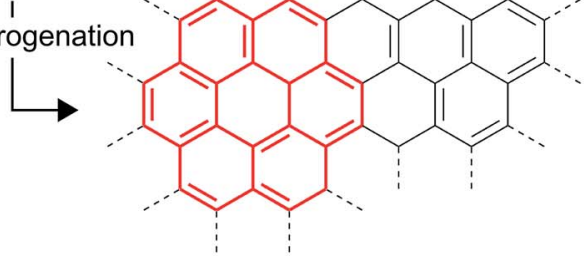

c)

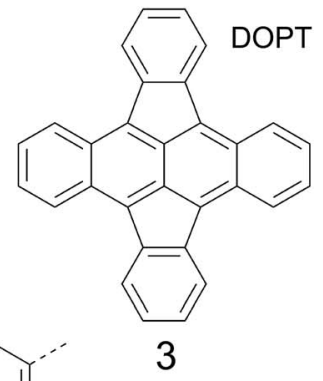

Fig. 1 Examples for thermal fusion reactions of (a) coronene (1) and (b) pentacene (2) by C-C coupling and cyclodehydrogenation to yield extended graphene-like structures. (c) Structure of the PAH 5,6;11,12-di-o-phenylenetetracene, DOPT, 3 studied herein.

is the most promising material for chemisensoric applications allowing a single molecule detection limit, ${ }^{34}$ integration into a sensor system can be complex and experimentally laborious. Carbon nanofibers may be inferior to graphene and even CNTs comparing their limits of detection, yet highyielding synthesis and simple integration in sensor setups make CNFs an interesting nanomaterial for the use in chemiresistors. ${ }^{33}$

\section{Experimental}

\section{Materials and preparation of substrates}

Synthesis of 5,6;11,12-di-o-phenylenetetracene was achieved as reported. ${ }^{22}$ Saturated solutions of DOPT in dichloromethane (DCM) were prepared by dissolving $2 \mathrm{mg}$ DOPT in $10 \mathrm{~mL}$ DCM. Needle-like crystals were deposited on individual substrates by simple drop coating of the as-prepared solution (Fig. 2). As substrates, copper foil (Alfa Aesar, 99.8\% purity, $0.025 \mathrm{~mm}$ thickness), $\mathrm{SiO}_{2} / \mathrm{Si}$ wafer (Si-Mat Silicon Materials, thermally grown $600 \mathrm{~nm} \mathrm{SiO}_{2}$ ) and $\mathrm{SiO}_{2} / \mathrm{Si}$ wafer coated with a $20 \mathrm{~nm}$ thick layer of platinum/palladium ( $\mathrm{Pt} / \mathrm{Pd}$ (80/20) disc, $99.99 \%$ purity, $0.1 \mathrm{~mm}$ thickness), which was deposited by sputter coating (Cressington sputter coater 208HR), were used.

\section{Thermal transformation of DOPT and synthesis of nanofibers}

Thermal transformation was done in a tube furnace (Fa. Horst, Lorsch, $300 \mathrm{~mm}$ in length, $30 \mathrm{~mm}$ tube diameter), connected to a multi gas controller (MKS Instruments Mass-Flow Controller, MKS Instruments Multi Gas Controller $647 \mathrm{C}$ ), pressure controller (Ilmvac VCZ 324) and vacuum pump. The quartz tube extends the length of the tube furnace. A magnetic holder is used to transfer the sample into the hot zone under reduced pressure and to remove them from the furnace immediately after treatment. Samples were placed in the magnetic holder and positioned in the quartz tube outside the hot zone. The setup is evacuated and the furnace is heated to $1000{ }^{\circ} \mathrm{C}(1 \mathrm{~h})$. Hydrogen (Air Liquide, 99.999 vol\% purity) is passed through the system and after a pressure of $10 \mathrm{mbar}$ is reached, the quartz tube is isolated from the set up by closing an inlet and outlet valve. The magnetic holder with samples is instantly placed in the middle of the tube furnace and kept their for either $0.5 \mathrm{~h}$ or $5 \mathrm{~h}$. After decomposition, the holder is removed from the hot zone into the cold part of the quartz tube (still under reduced pressure). Samples are cooled to room temperature in vacuum and after a few hours, the system is flushed with argon.
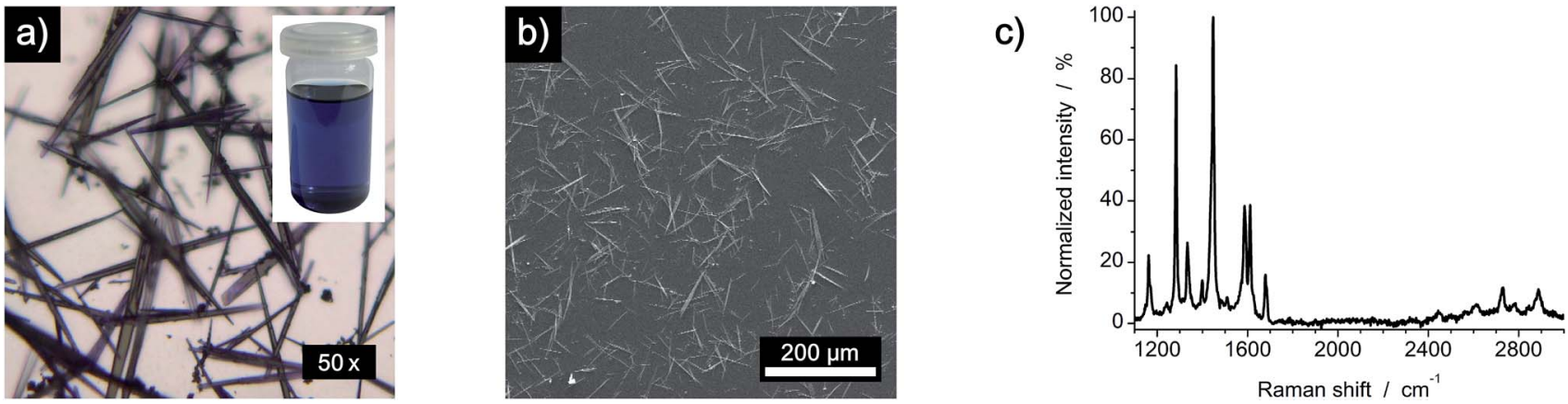

Fig. 2 Characterization of DOPT before thermal decomposition. (a) Microscopy image of needle-like crystals (inset: solution of DOPT in DCM). (b) SEM image of DOPT after deposition by drop coating. (c) Representative Raman spectrum of DOPT at an excitation wavelength of 514 nm. 


\section{Preparation of chemiresistors and characterization of sensor} performance

Chemiresistors are prepared by coating a commercially available sensor substrate (CeramTec) with a $20 \mathrm{~nm}$ thick layer of Pt/ Pd and DOPT as described before. Sensor substrates are made of alumina with interdigitated Pt electrodes on front side and a Pt heater on the back side (see Fig. S1 in ESI $\dagger$ ). Thermal decomposition of DOPT was done for $5 \mathrm{~h}$ using identical parameters as before. Gas sensor measurements are performed in a computer-controlled setup equipped with mass-flow controllers (MKS Instruments Mass-Flow Controller, MKS Instruments Multi Gas Controller 647 B), pyrometer (LumaSense Technologies IMPAC IN 5 plus-PL), power supply for temperature regulation (Voltcraft DPS 8003PFC) and a data acquisition/data logger switch unit (Agilent 34972A LXI) for logging electrical resistance of the sensor. A detailed scheme of the experimental setup is given in ref. 35. Pre-mixed gas mixtures of nitrogen dioxide ( $0.1 \mathrm{vol} \%)$, ammonia ( $0.01 \mathrm{vol} \%)$ and sulfur dioxide $(0.1 \mathrm{vol} \%)$ in nitrogen (Air Liquide, 99.999 vol\% purity) were additionally diluted with nitrogen (99.999 vol\% purity) and introduced into the glass reactor with the chemiresistor in defined concentration. Analyzed temperatures are $30^{\circ} \mathrm{C}$ and $200{ }^{\circ} \mathrm{C}$. The sensors response is given as $\Delta R /$ $R_{0}$ (in \%), were $R_{0}$ is the initial resistance in pure nitrogen and $\Delta R=R_{t}-R_{0}$ is the change in resistance at a given time $t$ in relation to $R_{0}$.

\section{Materials characterization}

Characterization by optical microscopy was carried out using Olympus CX40 at magnifications of $10 \times$ and $50 \times$. SEM (FEI, Philips XL30 FEG) was operated at an acceleration voltage of 30 kV. Micro-Raman spectroscopy (Horiba, LabRAM HR8000, Lab Spec 5) was carried out at a wavelength of $514.5 \mathrm{~nm}$ and a magnification of $50 \times$. Amorphous CNFs synthesized on copper foil were additionally transferred onto $\mathrm{SiO}_{2} / \mathrm{Si}$ by chemical etching for Raman analysis. For TEM characterization, a-CNFs were directly synthesized on a TEM support (Electron Microscopy Sciences) of either copper, $\mathrm{SiO}_{x}$ or a grid on which $20 \mathrm{~nm}$ of sputtered Pt/Pd had been deposited. TEM was done at an acceleration voltage of $200 \mathrm{keV}$ (FEI Tecnai G2F20@200 keV equipped with EDAX/EDS detector). Additionally, a-CNFs were transferred onto grids coated with lacey carbon film (Electron Microscopy Sciences, lacey carbon film on 300 mesh copper grid) by sonication of a TEM support in ethanol and drop coating of the as-prepared dispersion. XPS (ThermoFisher Scientific, K-Alpha XPS-Spectrometer) was performed using monochromatic aluminium $\mathrm{K}_{\alpha}$ radiation with an acceleration voltage of $8 \mathrm{kV}$.

\section{Results and discussion}

5,6;11,12-di-o-phenylenetetracene (DOPT) 1 precipitates from a toluene solution forming air and light stable needle-like crystals with a length of up to $100 \mu \mathrm{m}$. These were deposited on various substrates by drop coating using saturated solutions of DOPT in dichloromethane (Fig. 2). The as-prepared samples were rapidly heated to $1000{ }^{\circ} \mathrm{C}$ ( $<1 \mathrm{~min}$ ) inside a closed quartz tube under reduced pressure of 10 mbar in a hydrogen atmosphere. Finally, the reaction was terminated by removing the substrate from the hot zone of the furnace either after $0.5 \mathrm{~h}$ or $5 \mathrm{~h}$ reaction time. Morphological and spectroscopic analysis of the thermal transformation was done using optical microscopy (OM), scanning electron microscopy (SEM), transmission electron microscopy (TEM), micro-Raman spectroscopy (Raman) and X-ray photoelectron spectroscopy (XPS). To study the influence of the substrate on the conversion of DOPT into larger graphitic aggregates, three different substrates were investigated; copper foil, bare silicon dioxide/silicon wafer and a $20 \mathrm{~nm}$ thick layer of platinum/palladium (ratio of 80/20) deposited on $\mathrm{SiO}_{2} / \mathrm{Si}$ wafer by sputtering.

\section{Conversion reaction of DOPT on copper foil}

First, we analyzed the thermal decomposition of DOPT on copper foil used for the CVD synthesis of graphene using methane. ${ }^{36}$ In addition, parameters for the thermal decomposition of DOPT were chosen close to the established CVD process for the synthesis of CVD derived graphene. Thus, thermally induced fusion of the PAH 5,6;11,12-di-o-phenylenetetracene might yield graphene albeit in highly defective composition. Characterization of the annealed samples by optical microscopy confirmed indeed degradation of the needle-like crystals, leaving black coloured residues in similar morphology as the original DOPT crystals behind (Fig. 3a and b). Raman spectroscopy verifies the complete decomposition of DOPT. The D and G peak, which are characteristic for carbon nanomaterials, ${ }^{4}$ are present in the Raman spectra of these solid black residues (Fig. 3c). The intensity ratio D/G might be indicative for a successful synthesis of carbon nanotubes, nanofibers, ${ }^{37,38}$ or highly defective graphene. ${ }^{39}$ Micro-Raman analysis revealed that no carbonaceous material was present in the areas in between the dark material formed.

SEM images of the residues directly on the copper substrate after the thermal reaction of DOPT prove the synthesis of onedimensional nanostructures, which had grown in the positions, where crystals of the intact DOPT molecule were located (Fig. 4). To rule out the formation of graphene in the areas between the dark residues, the copper substrate was etched followed by a transfer process of hypothetically synthesized graphene onto a $\mathrm{SiO}_{2} / \mathrm{Si}$ wafer. However, no characteristic and indicative Raman peaks of graphene could be detected on the wafer. To finally distinguish carbon nanotubes from carbon nanofibers, DOPT was directly annealed on a copper TEM grid under identical conditions as before. The obtained onedimensional nanostructures show a highly flexible, solid structure and no sign of metallic incorporations (Fig. 5a and b). For further characterization the CNFs were transferred onto a lacey carbon coated TEM grid employing a short sonication procedure in ethanol followed by drop coating of the dispersion onto a TEM grid. TEM analysis revealed a completely amorphous structure of the CNFs (Fig. 5c). No regular platelet, cupstacked or herringbone type CNFs were observed (Fig. 5d). ${ }^{40}$ Even the chosen short sonication time resulted in a destruction 

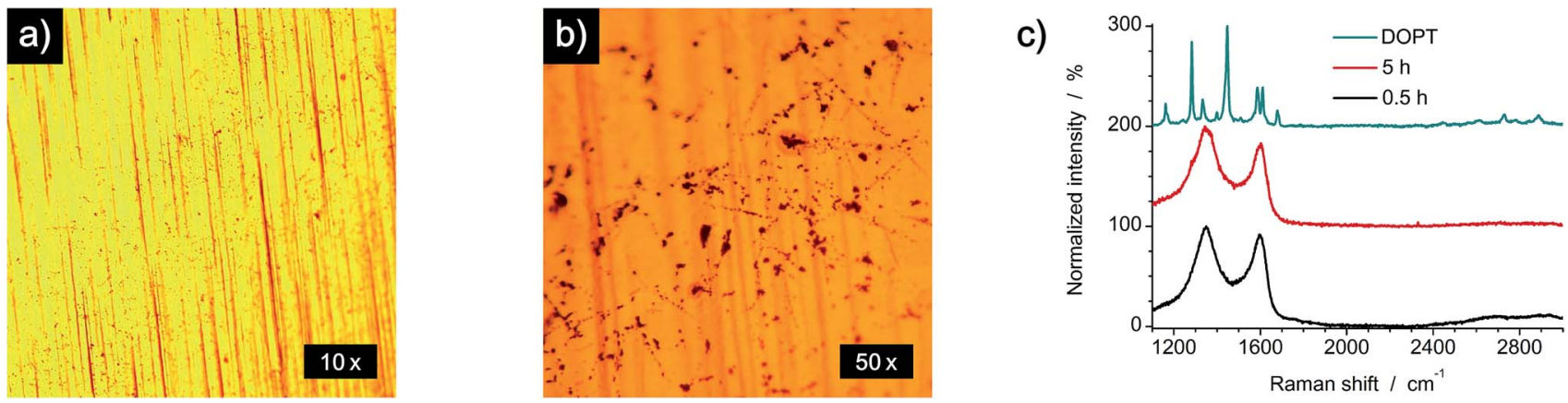

Fig. 3 Characterization of the copper substrate after thermal decomposition of DOPT at $1000^{\circ} \mathrm{C}$. (a and b) OM images at different magnifications. (c) Raman spectra of DOPT (cyan) and of black residues after thermal annealing at $1000^{\circ} \mathrm{C}$ for $0.5 \mathrm{~h}$ (black) and $5 \mathrm{~h}$ (red).
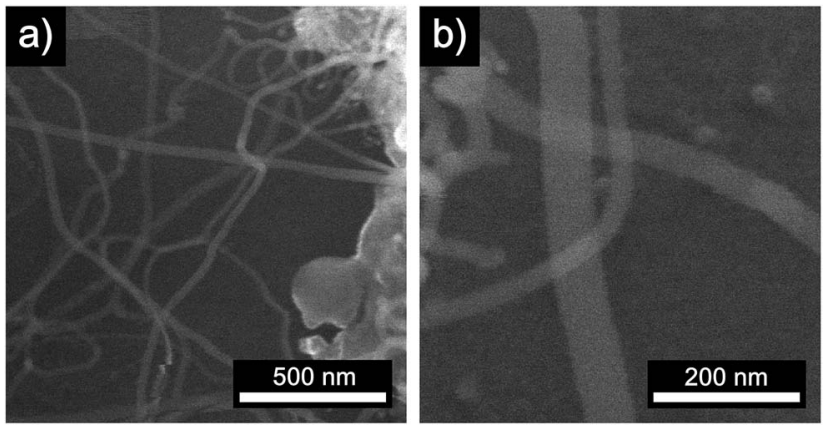

Fig. 4 SEM characterization of carbon nanostructures formed after thermal annealing of DOPT on copper foil at $1000^{\circ} \mathrm{C}$ for $5 \mathrm{~h}$, (a) and (b) show different magnifications.

of most a-CNFs, also confirming their composition of amorphous carbon. Neither Raman spectra nor SEM microscopic analysis indicated an effect of different annealing times on the structure or morphology of a-CNFs. Mean diameter of the aCNFs are between $30 \mathrm{~nm}$ and $40 \mathrm{~nm}$, yet isolated ones with $70 \mathrm{~nm}$ diameter have been detected.

\section{Conversion reaction of DOPT on a $\mathrm{SiO}_{2} / \mathrm{Si}$ wafer}

To analyze a possible catalytic effect of the copper substrate on the decomposition of DOPT, similar experiments as before were done using a $\mathrm{SiO}_{2} / \mathrm{Si}$ wafer as substrate. Analysis by OM, SEM, TEM and Raman spectroscopy confirms synthesis of amorphous carbon nanofibers similar to those formed on the copper substrate (Fig. 6). Black residues on the wafer were visualized by OM (Fig. 6a), whereas SEM images proved the growth of flexible, one-dimensional nanostructures in locations were DOPT crystals had been deposited originally (Fig. 6b). However, there was a significant diameter difference of the a-CNFs observed. The diameter of those increased for longer periods of annealing time from around $30 \mathrm{~nm}(0.5 \mathrm{~h})$ to $80 \mathrm{~nm}(5 \mathrm{~h})$. Corresponding SEM images are shown in Fig. S2 in ESI. $\dagger$ Analysis of a-CNFs by TEM, directly synthesized by a thermal reaction from DOPT at $1000{ }^{\circ} \mathrm{C}$ on a $\mathrm{SiO}_{x}$-TEM grid in order to mimic the $\mathrm{SiO}_{2} / \mathrm{Si}$ substrate but to exclude any change caused by transfer etc., shows again flexible a-CNFs similar to the ones observed on the bare copper substrate (Fig. 6c). Raman peaks and ratio of intensities agree as well (Fig. 6d). These results thus indicate no detectable catalytic effect of the previously analyzed copper substrate on the thermal decomposition of DOPT.

\section{Conversion reaction of DOPT on $20 \mathrm{~nm} \mathrm{Pt} / \mathrm{Pd}(80 / 20)$ deposited on $\mathrm{a} \mathrm{SiO}_{2} / \mathrm{Si}$ wafer}

Thermal decomposition of DOPT on a $20 \mathrm{~nm}$ thick layer of platinum/palladium (ratio of $80 \% \mathrm{Pt}$ to $20 \% \mathrm{Pd}$ ), which was deposited on $\mathrm{SiO}_{2} / \mathrm{Si}$ wafer (600 $\mathrm{nm}$ thermally grown $\mathrm{SiO}_{2}$ ) by sputter coating was also analyzed. As both noble metals are
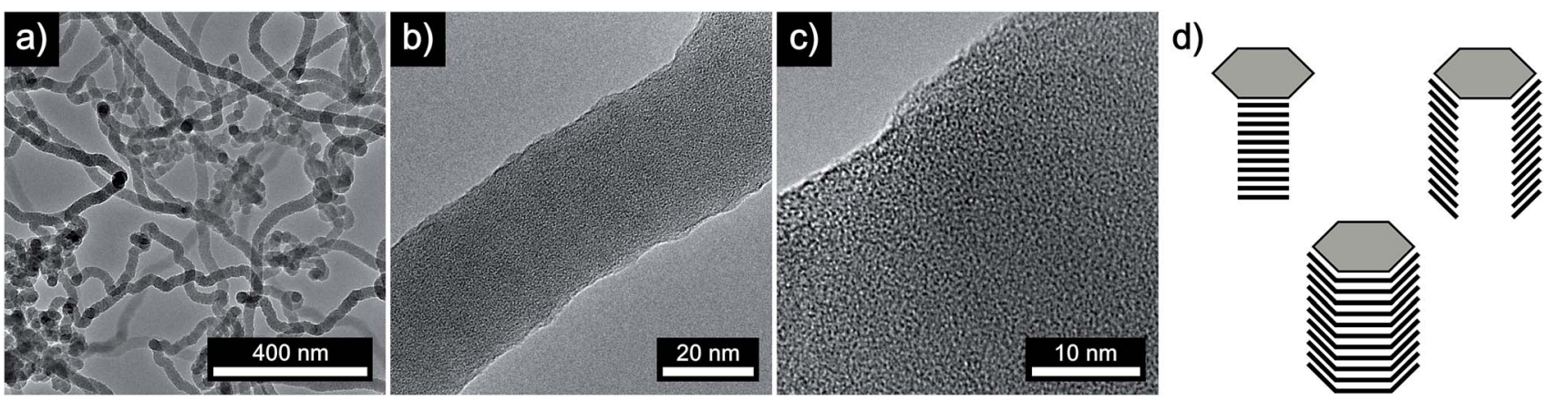

Fig. 5 Characterization of one-dimensional carbon nanostructures after thermal annealing of DOPT on a copper TEM grid at $1000{ }^{\circ} \mathrm{C}$ for $5 \mathrm{~h}$. (a and b) Direct synthesis of a-CNFs on a copper grid and (c) transferred a-CNFs on a lacey carbon coated TEM grid obtained by sonication in ethanol and drop coating. (d) Typical orientation of graphitic layers in crystalline CNFs: platelet, cup-stacked and herringbone type (left to right). 

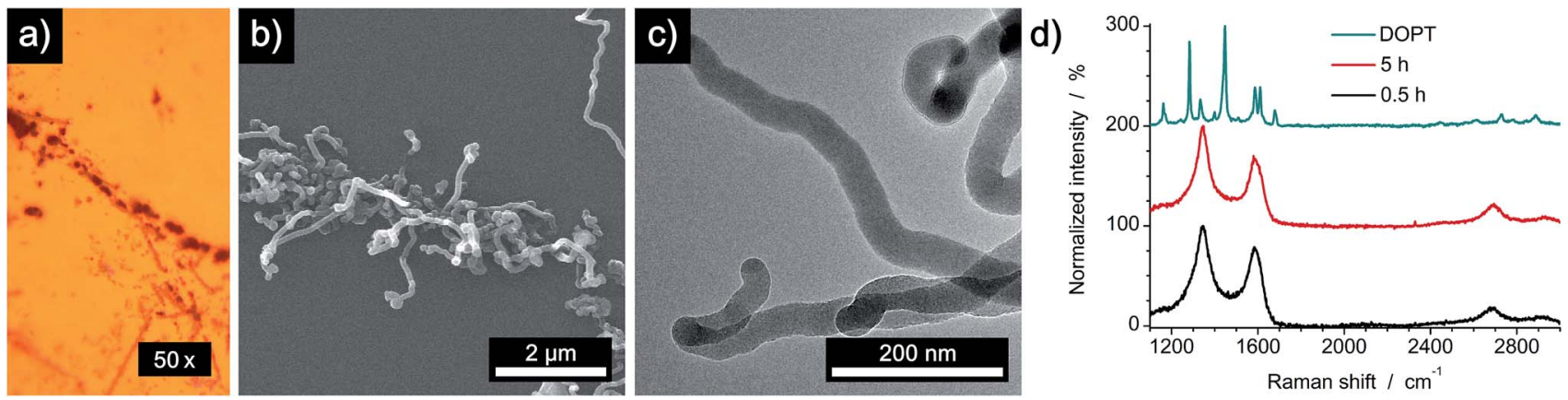

Fig. 6 Characterization of a-CNFs after thermal annealing of DOPT on a $\mathrm{SiO}_{2} / \mathrm{Si}$ wafer and on a $\mathrm{SiO}_{x}-\mathrm{TEM}$ substrate at $1000^{\circ} \mathrm{C}$ for $5 \mathrm{~h}$. (a) Optical micrograph image of a-CNFs on a $\mathrm{SiO}_{2} / \mathrm{Si}$ wafer. (b) SEM image of one-dimensional nanostructures. (c) TEM image of a-CNFs directly synthesized on a $\mathrm{SiO}_{x}-\mathrm{TEM}$ grid. (d) Raman spectra of DOPT (cyan) and of a-CNFs synthesized on a $\mathrm{SiO}_{2} / \mathrm{Si}$ wafer after thermal conversion of DOPT at $1000{ }^{\circ} \mathrm{C}$ for $0.5 \mathrm{~h}$ (black) and $5 \mathrm{~h}(\mathrm{red})$

known to be catalytically active metals in the synthesis of onedimensional carbon nanomorphologies, an improved synthesis of a-CNFs was expected. ${ }^{41}$ Analysis by OM indicated a similar thermal decomposition as compared to bare $\mathrm{Cu}$ and $\mathrm{SiO}_{2} / \mathrm{Si}$ substrates as a dark residue was observed after decomposition. However, the colour of the surface changed drastically and it became inhomogeneous during annealing (Fig. 7a). SEM images prove formation of $\mathrm{Pt} / \mathrm{Pd}$ nanoparticles with an average diameter of $300 \mathrm{~nm}$ and also confirm a remarkably increased quantity of as-synthesized a-CNFs as compared to $\mathrm{Cu}$ and $\mathrm{SiO}_{2} /$ Si substrates (Fig. 7b). Although the number of fibers and/or their length has increased considerably, their average diameter of $30-40 \mathrm{~nm}$ is still in the same range as on the former substrates. The increase in synthesis time from $0.5 \mathrm{~h}$ (see Fig. S3 in ESI $\dagger$ ) to five hours even improved the quantity of a-CNFs. They form a very dense network on the substrate. Analysis by TEM (Fig. 7c) and Raman spectroscopy (Fig. 7d) shows similar results for the grown CNFs.

A comparison of the obtained a-CNF diameters on all three substrates is given in Fig. 8a. Whereas most carbon nanofibers have an average diameter of $30-40 \mathrm{~nm}$, synthesis of a-CNFs on $\mathrm{SiO}_{2} / \mathrm{Si}$ for a total reaction time of $5 \mathrm{~h}$ resulted in an increase in diameter to $80 \mathrm{~nm}$. In relation to the size of the $\mathrm{Pt} / \mathrm{Pd}$ nanoparticles the diameter of the a-CNFs is much lower, indicating the growth of multiple fibers on a single metal particle (Fig. 8b).
As-prepared networks of carbon nanofibers on $\mathrm{Pt} / \mathrm{Pd}$ nanoparticles and $\mathrm{SiO}_{2} / \mathrm{Si}$ substrate were also analyzed by X-ray photoelectron spectroscopy (Fig. 9). XPS spectra reveal the expected presence of carbon, silicon and oxygen, yet platinum and palladium can not be detected. As XPS typically has a penetration depth of only a few nanometers into the surface, these results indicate a complete coverage of the catalyst nanoparticles with a several nanometer thick layer of carbon. This also indicates the initial growth of a-CNFs at the metallic nanoparticles by thermal decomposition of DOPT. The XPS C 1s signal is fitted with four components in the appropriate ratio of $35.4 \% \mathrm{C}-\mathrm{C} \mathrm{sp}{ }^{2}, 51.7 \% \mathrm{C}-\mathrm{C} \mathrm{sp}^{3}, 10.7 \% \mathrm{C}-\mathrm{O}$ and $2.2 \%$ of $\mathrm{O}-\mathrm{C}=\mathrm{O}$ moieties, respectively. As discrimination of $\mathrm{sp}^{2}$ and $\mathrm{sp}^{3}$ carbon species is difficult, given values are an estimation, yet they are in full agreement with Raman spectra of the a-CNFs. Oxygen based functional groups can either be generated by reaction of a-CNFs with the $\mathrm{SiO}_{2}$ substrate or steaming from oxygen residues residing in the quartz tube walls during gas phase synthesis.

We further analyzed the synthesis of carbon nanofibers on thin layers of $\mathrm{Pt} / \mathrm{Pd}$ at temperatures of $800{ }^{\circ} \mathrm{C}, 600{ }^{\circ} \mathrm{C}, 400{ }^{\circ} \mathrm{C}$ and $200^{\circ} \mathrm{C}$. Visual analysis by OM (see Fig. S4 in ESI $\dagger$ ) and SEM (Fig. 10 and S5 in ESI $\dagger$ ) shows no comparable formation of carbon nanostructures at temperatures lower than $1000^{\circ} \mathrm{C}$ as it was observed in the other reactions. The formation of nanoparticles from the deposited films is limited to temperatures of
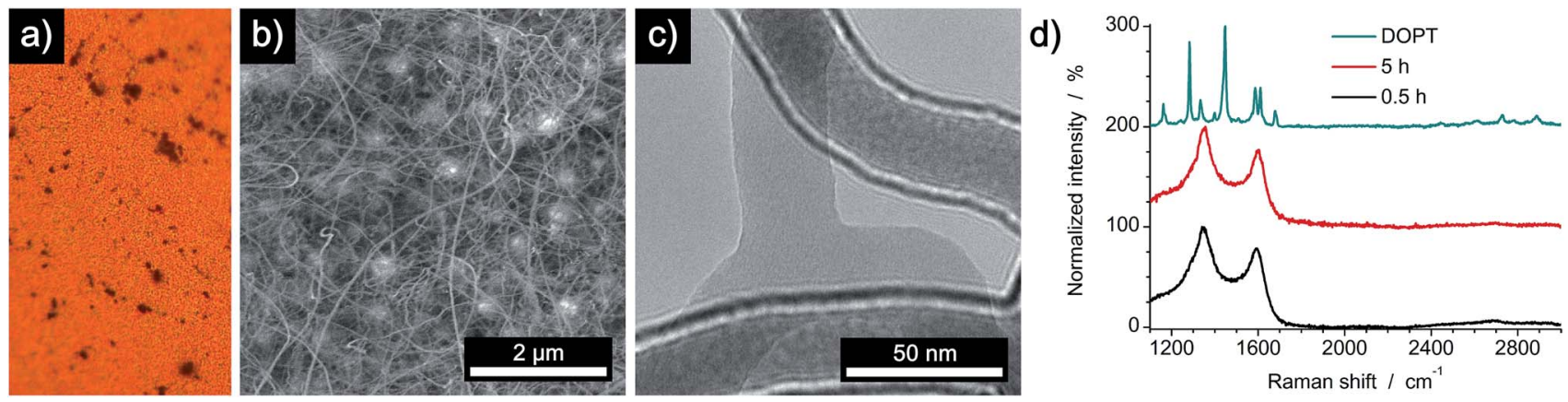

Fig. 7 Characterization of carbon nanofibers after thermal annealing of DOPT on Pt/Pd and $\mathrm{SiO}_{2} / \mathrm{Si}$ at $1000{ }^{\circ} \mathrm{C}$ for $5 \mathrm{~h}$. (a) OM image of residues on the substrate. (b) SEM image of Pt/Pd nanoparticles and network of a-CNFs. (c) TEM image of a-CNFs synthesized on TEM support. (d) Raman spectra of DOPT (cyan) and of a-CNFs after annealing at $1000{ }^{\circ} \mathrm{C}$ for $0.5 \mathrm{~h}$ (black) and $5 \mathrm{~h}$ (red). 
a)

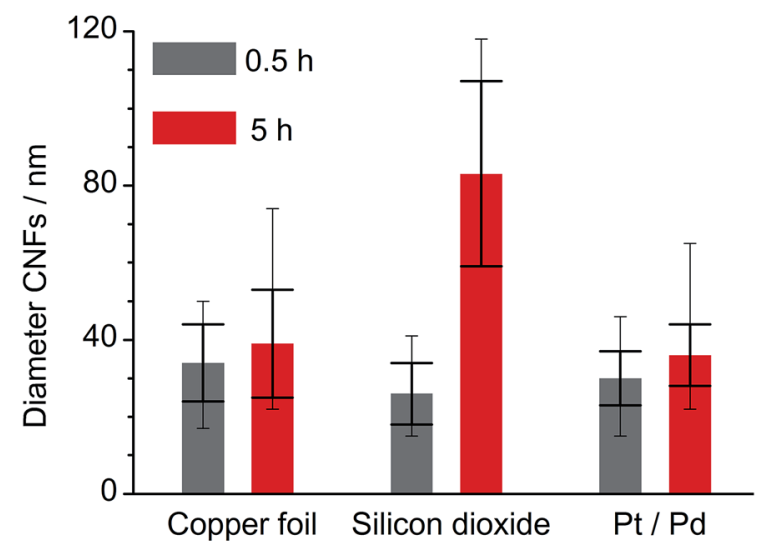

b)

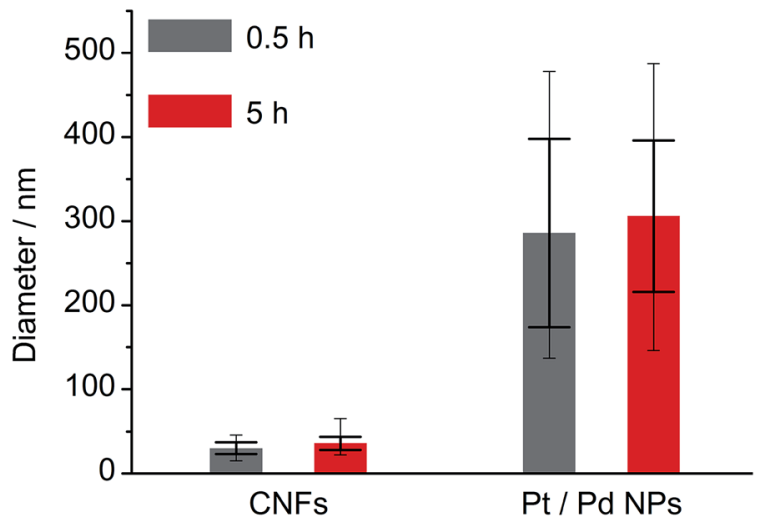

Fig. 8 Analysis of (a) the diameter variation of a-CNFs, depending on the substrate and the time of annealing at $1000{ }^{\circ} \mathrm{C}$, as well as (b) comparison between a-CNF diameter and size of the Pt/Pd nanoparticles. Larger error bars indicate standard deviation, whereas smaller error bars indicate maximum and minimum numbers of all analyzed diameters.

$800{ }^{\circ} \mathrm{C}$ as minimum. However, a change in Raman spectra of all samples can be detected, indicating that reaction of DOPT may even start at lower temperatures. From $600{ }^{\circ} \mathrm{C}$ and higher, defined $\mathrm{D}$ and $\mathrm{G}$ peak can be distinguished, e.g. growth of aCNFs may start but is insufficient to be detected neither by SEM nor TEM.

\section{Study of amorphous carbon nanofibers as chemiresistive gas sensor material}

We further analyzed the amorphous carbon nanofibers in a chemiresistive gas sensor for detection of $\mathrm{NO}_{2}, \mathrm{NH}_{3}$ and $\mathrm{SO}_{2}$. To avoid transfer and contacting of the one-dimensional nanostructures, we intended to synthesize a-CNFs directly on a sensor substrate. Commercially available sensor substrates are made of alumina with platinum electrodes on the front and a platinum heater on the back side (see Fig. S1 in ESI†). First, a bare layer of platinum/palladium was sputtered on this sensor substrate, resulting in a detectable resistance of about $40 \Omega$ (Fig. 11). After annealing this substrate at $1000{ }^{\circ} \mathrm{C}$ without DOPT, formation of nanoparticles occurs on the alumina substrate by dewetting of the as-deposited film. No resistance could be measured (maximum of detectable resistance is 120 $\mathrm{M} \Omega$ ). In another experiment a layer of $\mathrm{Pt} / \mathrm{Pd}$ and DOPT were a)

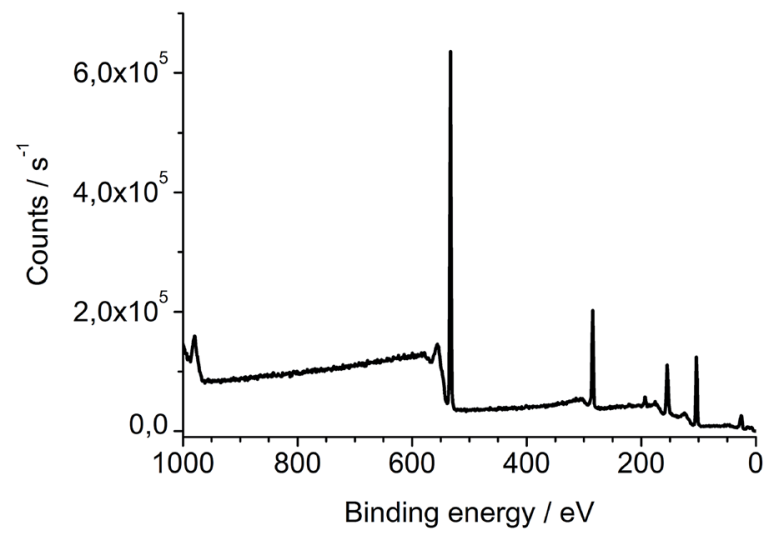

b)

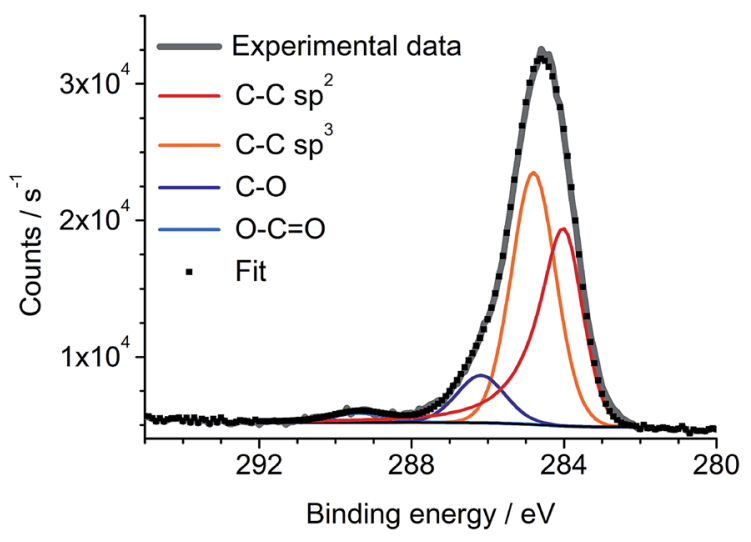

Fig. 9 Characterization of a-CNFs by XPS, synthesized by thermal annealing of DOPT on $\mathrm{Pt} / \mathrm{Pd}$ and $\mathrm{SiO}_{2} / \mathrm{Si}$ at $1000{ }^{\circ} \mathrm{C}$ for $5 \mathrm{~h}$. (a) Survey spectrum and (b) $C$ 1s spectrum of as-prepared a-CNFs on the substrate. Curve fitting was done using a Shirley background and a four component fitting $\mathrm{C}-\mathrm{C} \mathrm{sp}^{2}, \mathrm{C}-\mathrm{C} \mathrm{sp}^{3}, \mathrm{C}-\mathrm{O}$ and $\mathrm{O}-\mathrm{C}=\mathrm{O}$ was employed.

deposited on a sensor substrate, yielding $\mathrm{Pt} / \mathrm{Pd}$ nanoparticles and a dense network of carbon nanofibers after thermal processing at $1000^{\circ} \mathrm{C}$. As the bare layer of Pt/Pd did not show any detectable resistance after annealing, resistance of $1 \mathrm{M} \Omega$ refers to the network of a-CNFs. Analysis of the a-CNFs by OM, SEM and Raman (see Fig. S6 in ESI †े) confirms similar results compared to decomposition of DOPT on $20 \mathrm{~nm} \mathrm{Pt} / \mathrm{Pd}$ and $\mathrm{SiO}_{2} /$ $\mathrm{Si}$ substrates as discussed before. In agreement with the amorphous structure of the a-CNFs, their measurable resistance is high and the initial resistance in inert gas atmosphere shows a high noise. Yet, as-prepared networks of fibers can be applied in chemiresistors for the detection of toxic gases. As XPS measurements indicated a complete coverage of the catalyst nanoparticles with a several nanometer thick layer of carbon is observed. An effect of Pt/Pd particles on the sensor performance is therefore not expected. In addition, pure DOPT was analyzed on a bare sensor substrate. As DOPT has a band gap of $2.2 \mathrm{eV},{ }^{23}$ no resistance can be detected at room temperature. Also, thermal decomposition of DOPT on the bare sensor substrate did not result in any measurable chemiresistor behaviour, as the short length and low density of the formed a-CNFs prevent contacting of the sensor electrodes. 

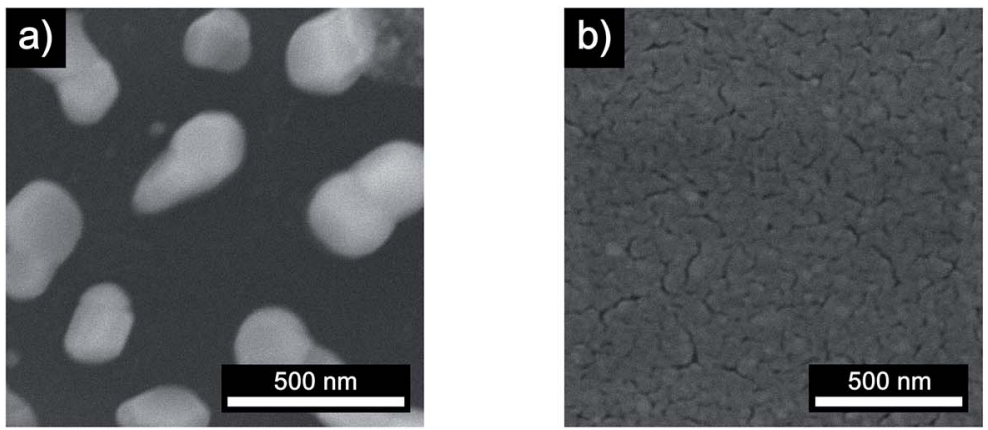

c)

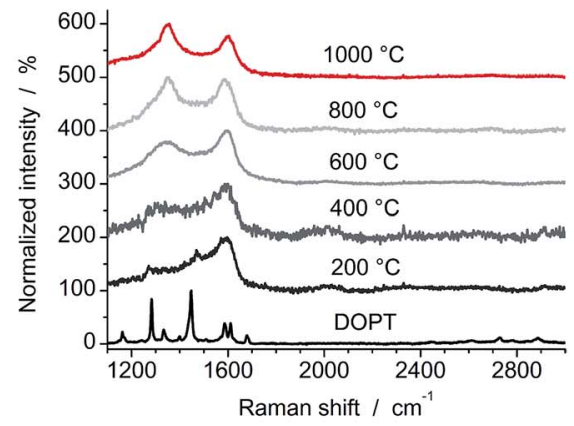

Fig. 10 Effect of decreasing annealing temperatures on the thermal decomposition of DOPT on Pt/Pd and SiO $/ 2$ Si. SEM images of samples after annealing at (a) $800{ }^{\circ} \mathrm{C}$ and (b) $600{ }^{\circ} \mathrm{C}$ for $5 \mathrm{~h}$. (c) Raman spectra of individual samples before (bottom) and after annealing at the given temperatures for $5 \mathrm{~h}$.

Dynamic response of the as-prepared chemiresistors with $R_{0}=1 \mathrm{M} \Omega$ was analyzed in a nitrogen atmosphere at $30^{\circ} \mathrm{C}$ and $200{ }^{\circ} \mathrm{C}$ with the gases $\mathrm{NO}_{2}, \mathrm{NH}_{3}$ and $\mathrm{SO}_{2}$. Concentration of $\mathrm{NO}_{2}$ and $\mathrm{SO}_{2}$ is in the range of $10-500 \mathrm{ppm}$, whereas concentration of $\mathrm{NH}_{3}$ is in the range of $10-50 \mathrm{ppm}$. Instead of plotting the detected real-time resistance $R_{t}$, relative change in resistance $\left(R_{t}\right.$ $-R_{0}$ ) normalized to the initial resistance $R_{0}$ is shown in Fig. 12 . The dense network of a-CNFs shows p-type characteristic, as resistance decreases by exposure to the electron acceptors $\mathrm{NO}_{2}$ and $\mathrm{SO}_{2}$ (e.g. $\Delta R / R_{0}<0 \%$ ), whereas a slight increase is detected by exposure to the electron donor $\mathrm{NH}_{3}$ (e.g. $\Delta R / R_{0}>0 \%$ ). Yet, response of the chemiresistor to $\mathrm{NH}_{3}$ is negligible low at all temperatures and hardly exceeds the noise signal of the initial resistance. By comparison, exposure to a similar concentration of $\mathrm{NO}_{2}$ and $\mathrm{SO}_{2}$ results in higher response, yet it decreases with increasing temperature (Fig. 12a and c). Whereas recovery of the a-CNFs is negligible low at room temperature, it clearly improves at $200{ }^{\circ} \mathrm{C}$.
In theory, two possible sensing mechanisms can be expected for the hybrid composite material: (1) gas molecules adsorb onto the $\mathrm{Pt} / \mathrm{Pd}$ nanoparticles and induce a charge transfer between particles and CNFs. This charge transfer could eventually change the electrical conductivity, e.g. resistance, of the CNF network. Yet, as XPS results indicate a complete coverage of the Pt/Pd nanoparticles with a thick layer of carbon, an influence of $\mathrm{Pt} / \mathrm{Pd}$ is not to be expected. This first mechanism is therefore negligible. (2) Gas molecules adsorb onto the surface of the CNF network, which provides a continuous pathway for charge carriers between the two electrodes. Depending on the analyte gas, electrons are either transferred from the CNFs to the gas $\left(\mathrm{NO}_{2}\right.$ and $\mathrm{SO}_{2}$ act as electron acceptors) or from the gas molecules to the CNFs ( $\mathrm{NH}_{3}$ acts as electron donor). When exposed to $\mathrm{NO}_{2}$ and $\mathrm{SO}_{2}$, an increasing number of holes in the CNFs results in a decrease in the electrical resistance, e.g. $\Delta R / R_{0}$ $<0 \%$, because CNFs act as p-type transducers..$^{27,28,30}$ In contrast, exposure to $\mathrm{NH}_{3}$ increases the number of electrons and

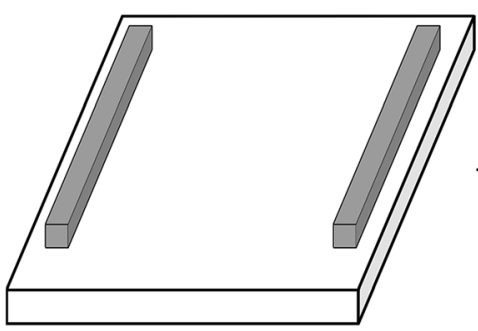

Sensor substrate
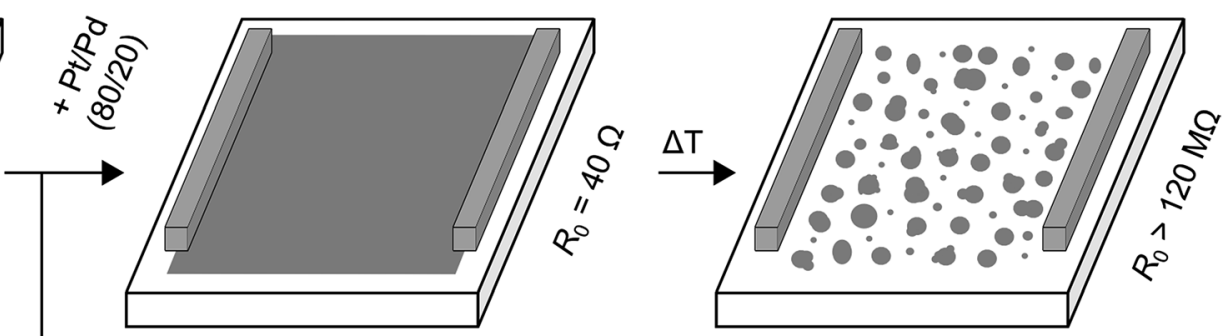

$+\mathrm{Pt} / \mathrm{Pd}(80 / 20)$

+ DOPT
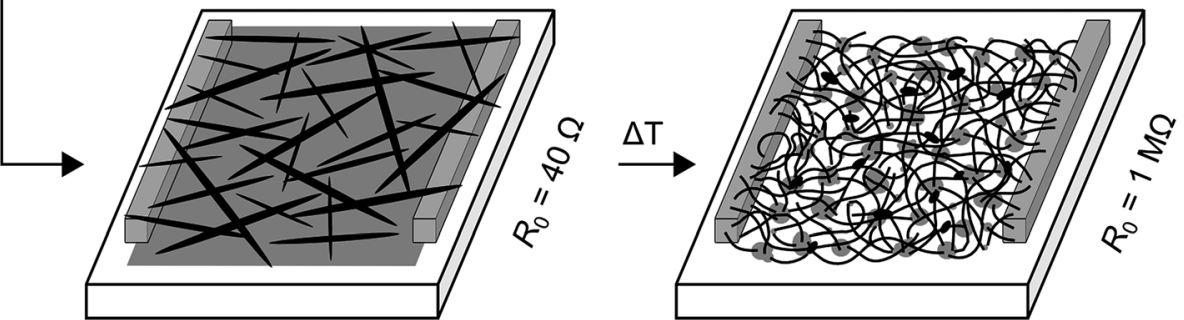

Fig. 11 Scheme showing formation of a-CNFs on a sensor substrate. First, a sputtered layer of $20 \mathrm{~nm}$ Pt/Pd was analyzed. After heating at $1000{ }^{\circ} \mathrm{C}$ for $5 \mathrm{~h}$ without DOPT, the conducting metallic layer became insulating due to dewetting of the deposited film and formation of isolated $\mathrm{Pt} / \mathrm{Pd}$ nanoparticles (upper trace). Deposition of DOPT on a layer of Pt/Pd followed by heating the sensor surface to $1000{ }^{\circ} \mathrm{C}$ resulted in dewetting and Pt/Pd particle formation and DOPT conversion into a dense network of a-CNFs with a $R_{0}$ of $1 \mathrm{M} \Omega$ (lower trace). $R_{0}$ is the initial resistance in pure nitrogen and can be detected for values of up to $120 \mathrm{M} \Omega$. For experimental sensor set up see ref. 35. 
a)

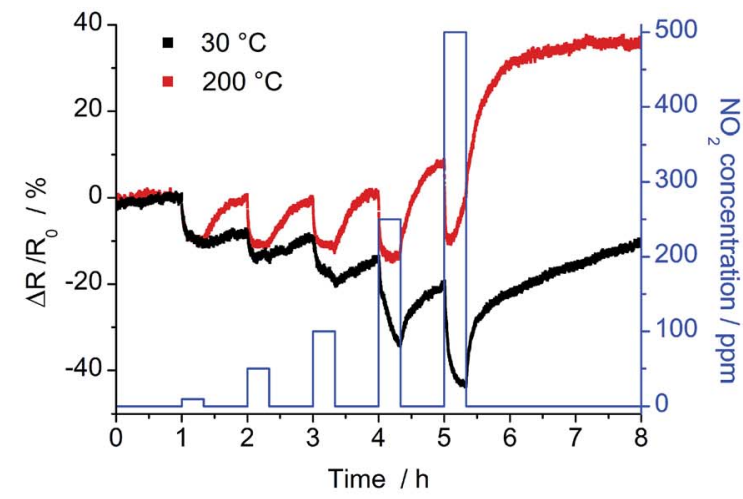

c)

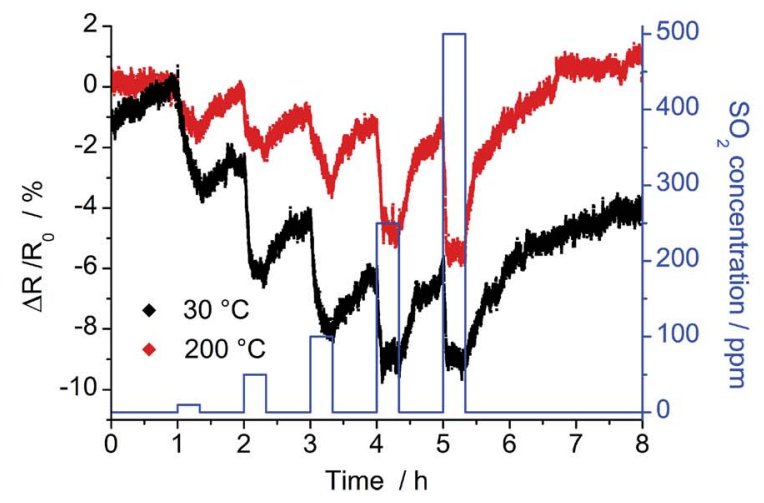

b)

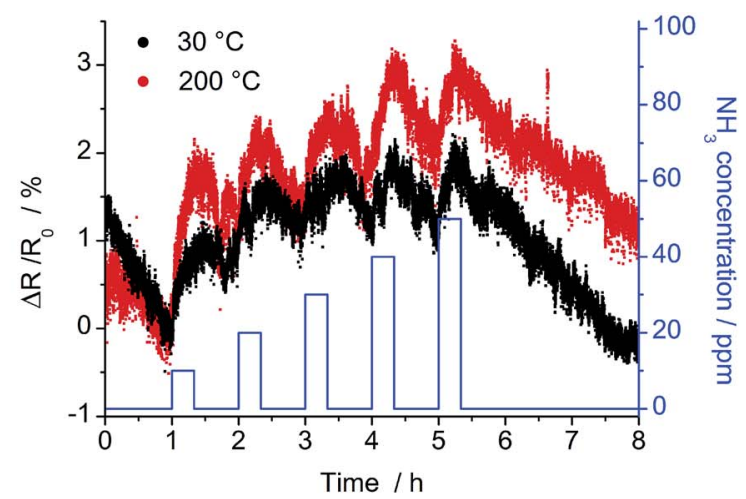

d)

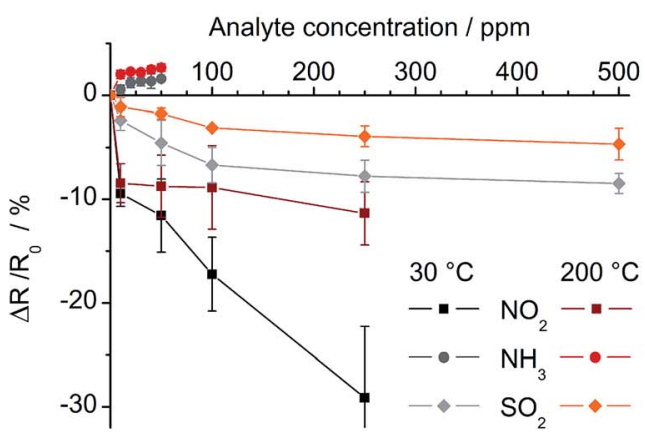

Fig. 12 Dynamic sensor response and calibration curves of the a- $\mathrm{CNF}$ network after exposure to $\mathrm{NO}_{2}, \mathrm{NH}_{3}$ and $\mathrm{SO}_{2}$ at $30{ }^{\circ} \mathrm{C}$ (black) and $200{ }^{\circ} \mathrm{C}$ (red) in nitrogen. Time of exposure to increasing concentration of analyte gas is 20 min, followed by 40 min of purging with pure nitrogen. (a) Exposure to 10, 50,100, 250 and 500 ppm of $\mathrm{NO}_{2}$. (b) Exposure to 10, 20, 30, 40 and 50 ppm of $\mathrm{NH}_{3}$. (c) Exposure to 10, 50, 100, 250 and $500 \mathrm{ppm}$ of $\mathrm{SO}_{2}$. (d) Correlating calibration curves of the as-prepared chemiresistor.

therefore leads to an increase in electrical resistance. As theoretical calculations prove that the charge transfer from ammonia to carbon nanomaterials is low compared to $\mathrm{NO}_{2}$ and $\mathrm{SO}_{2}$, change in resistance is smaller, confirming the given results. ${ }^{42,43}$

Lower detection limit (LOD) was calculated by fitting calibration curves (Fig. 12d) with linear and Langmuir isotherms. For a time of exposure of $20 \mathrm{~min}$ at $30{ }^{\circ} \mathrm{C}$, calculated LODs are

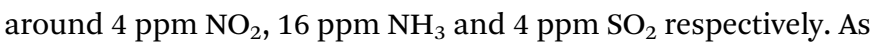
the change in resistance for lower concentration of analyte gas does not reach a constant value in $20 \mathrm{~min}$, the LODs could even be improved by extending the time of exposure.

Calculated LODs of few parts per million are comparable to chemiresistors fabricated of crystalline carbon nanofibers and are even similar to functionalized fibers decorated with metal nanoparticles..$^{27,28,30,44,45}$ Yet, one-dimensional single-walled carbon nanotubes detect amounts as low as $125 \mathrm{ppt} \mathrm{NO}_{2}{ }^{24}$ and $3 \mathrm{ppb} \mathrm{NH}_{3} \cdot{ }^{46} \mathrm{~A}$ comparison of sensor data of different carbon materials is given in Table S1 in ESI. $\dagger$

To the best of our knowledge, detection of sulfur dioxide using chemiresistors made of carbon nanofibers has not been analyzed yet. Accordingly, given results may act as reference data for future research. Incomplete recovery at room temperature is a general problem for application of carbon nanomaterials in gas sensors and is not limited to carbon nanofibers. Besides increasing the temperature, which simultaneously lowers their sensoric response, irradiation by UV-light also allows fast desorption of analyte molecules. ${ }^{27,44}$ Main advantage of the as-prepared chemiresistors using a-CNFs is their straightforward and effective method of fabrication. As the a-CNFs are directly synthesized on the substrate connecting the electrodes, any additional treatments, e.g. transfer and/or applying an electrical contact, is unnecessary.

\section{Conclusions}

In summary, amorphous carbon nanofibers, a-CNFs, have been synthesized by thermal transformation of the polycyclic aromatic hydrocarbon 5,6;11,12-di-o-phenylenetetracene, DOPT, 3 at $1000{ }^{\circ} \mathrm{C}$. Rapid annealing of DOPT on a copper substrate, on a $\mathrm{SiO}_{2} / \mathrm{Si}$ substrate or a $20 \mathrm{~nm}$ thick layer of $\mathrm{Pt} / \mathrm{Pd}$ on $\mathrm{SiO}_{2} / \mathrm{Si}$ yielded highly flexible, amorphous CNFs with an average diameter of 30-40 $\mathrm{nm}$. The quantity of a-CNFs increased drastically when $\mathrm{Pt} / \mathrm{Pd}$ particles, formed from $\mathrm{Pt} / \mathrm{Pd}$ thin films by dewetting at temperatures above $800{ }^{\circ} \mathrm{C}$, were used on $\mathrm{SiO}_{2} / \mathrm{Si}$ substrates compared to metal free substrates. As-synthesized dense networks of amorphous CNFs were applied in chemiresistors for the detection of toxic gases $\mathrm{NO}_{2}$, $\mathrm{NH}_{3}$ and $\mathrm{SO}_{2}$. All fabricated sensors showed good response to low concentration of $\mathrm{NO}_{2}$ and $\mathrm{SO}_{2}$, whereas change in resistance is negligible low for exposure to $10-50 \mathrm{ppm} \mathrm{NH}_{3}$. 


\section{Conflicts of interest}

There are no conflicts to declare.

\section{Acknowledgements}

TEM measurements were performed at the Ernst-RuskaZentrum for Elektronenmikroskopie (ER-C), Jülich, Germany, under the cooperative research program ERC-TUD 01. We thank J. Engstler (TUDa) for TEM measurements and L. Houben at ERC Jülich for technical assistance. XPS measurements were carried out with the support of the Karlsruhe Nano Micro Facility (KNMF), a Helmholtz research infrastructure at KIT, Karlsruhe, Germany. We acknowledge M. Bruns (KIT) for performing XPS measurement and J. Krausmann (TUDa) for measuring Raman spectra.

\section{Notes and references}

1 Y. Gogotsi and V. Presser, Carbon Nanomaterials, CRC Press, 2nd edn, 2013.

2 W.-W. Liu, S.-P. Chai, A. R. Mohamed and U. Hashim, J. Ind. Eng. Chem., 2014, 20, 1171-1185.

3 A. M. Schwenke, S. Hoeppener and U. S. Schubert, Adv. Mater., 2015, 27, 4113-4141.

4 A. Jorio, R. Saito, G. Dresselhaus and M. S. Dresselhaus, in Raman Spectroscopy in Graphene Related Systems, WileyVCH Verlag GmbH \& Co. KGaA, Weinheim, Germany, 2011, pp. 1-15.

5 X. Chen, L. Zhang and S. Chen, Synth. Met., 2015, 210, 95108.

6 K. A. Shah and B. A. Tali, Mater. Sci. Semicond. Process., 2016, 41, 67-82.

7 X. Jiang, Phys. Status Solidi A, 2014, 211, 2679-2687.

8 S. Kleckley, H. Wang, I. Oladeji, L. Chow, T. K. Daly, P. R. Buseck, T. Solouki and A. Marshall, in Synthesis and Characterization of Advanced Materials, American Chemical Society, 1997, pp. 51-60.

9 K. Koziol, B. O. Boskovic and N. Yahya, Characterisation and Applications, in Carbon and Oxide Nanostructures - Synthesis, Springer, 2011, pp. 23-49.

10 X. Qi, C. Qin, W. Zhong, C. Au, X. Ye and Y. Du, Materials, 2010, 3, 4142-4174.

11 C. N. He, N. Q. Zhao, C. S. Shi and S. Z. Song, J. Alloys Compd., 2009, 484, 6-11.

12 Y. Ishii, T. Sakashita, S. Kawasaki, H. Kato and M. Takatori, Mater. Express, 2011, 1, 36-42.

13 A. V. Talyzin, S. M. Luzan, K. Leifer, S. Akhtar, J. Fetzer, F. Cataldo, Y. O. Tsybin, C. W. Tai, A. Dzwilewski and E. Moons, J. Phys. Chem. C, 2011, 115, 13207-13214.

14 X. Wang, L. Zhi, N. Tsao, Ž. Tomović, J. Li and K. Müllen, Angew. Chem., Int. Ed., 2008, 47, 2990-2992.

15 X. Wan, K. Chen, D. Liu, J. Chen, Q. Miao and J. Xu, Chem. Mater., 2012, 24, 3906-3915.

16 T. Hayakawa, Y. Ishii and S. Kawasaki, RSC Adv., 2016, 6, 22069-22073.
17 J. Cai, P. Ruffieux, R. Jaafar, M. Bieri, T. Braun, S. Blankenburg, M. Muoth, A. P. Seitsonen, M. Saleh, X. Feng, K. Müllen and R. Fasel, Nature, 2010, 466, 470-473.

18 J. Cai, C. A. Pignedoli, L. Talirz, P. Ruffieux, H. Söde, L. Liang, V. Meunier, R. Berger, R. Li, X. Feng, K. Müllen and R. Fasel, Nat. Nanotechnol., 2014, 9, 896-900.

19 K. A. Simonov, N. A. Vinogradov, A. S. Vinogradov, A. V. Generalov, E. M. Zagrebina, G. I. Svirskiy, A. A. Cafolla, T. Carpy, J. P. Cunniffe, T. Taketsugu, A. Lyalin, N. Mårtensson and A. B. Preobrajenski, ACS Nano, 2015, 9, 8997-9011.

20 D. G. de Oteyza, A. García-Lekue, M. Vilas-Varela, N. MerinoDíez, E. Carbonell-Sanromà, M. Corso, G. Vasseur, C. Rogero, E. Guitián, J. I. Pascual, J. E. Ortega, Y. Wakayama and D. Peña, ACS Nano, 2016, 10, 9000-9008. 21 H. J. Lai, M. C. C. Lin, M. H. Yang and A. K. Li, Mater. Sci. Eng., C, 2001, 16, 23-26.

22 T. Wombacher, S. Foro and J. J. Schneider, Eur. J. Org. Chem., 2016, 2016, 569-578.

23 T. Wombacher, A. Gassmann, S. Foro, H. von Seggern and J. J. Schneider, Angew. Chem., Int. Ed., 2016, 55, 6041-6046.

24 D. Kumar, P. Chaturvedi, P. Saho, P. Jha, A. Chouksey, M. Lal, J. S. B. S. Rawat, R. P. Tandon and P. K. Chaudhury, Sens. Actuators, B, 2017, 240, 1134-1140.

25 A. Goldoni, R. Larciprete, L. Petaccia and S. Lizzit, J. Am. Chem. Soc., 2003, 125, 11329-11333.

26 M. M. Rana, D. S. Ibrahim, M. R. Mohd Asyraf, S. Jarin and A. Tomal, Sens. Rev., 2017, 37, 127-136.

27 J. S. Lee, O. S. Kwon, D. H. Shin and J. Jang, J. Mater. Chem. A, 2013, 1, 9099-9106.

28 L. Liao, M. Zheng, Z. Zhang, B. Yan, X. Chang, G. Ji, Z. Shen, T. Wu, J. Cao, J. Zhang, H. Gong, J. Cao and T. Yu, Carbon, 2009, 47, 1841-1845.

29 L. Zhang, X. Wang, Y. Zhao, Z. Zhu and H. Fong, Mater. Lett., 2012, 68, 133-136.

30 S. Claramunt, O. Monereo, M. Boix, R. Leghrib, J. D. Prades, A. Cornet, P. Merino, C. Merino and A. Cirera, Sens. Actuators, B, 2013, 187, 401-406.

31 F. Yavari and N. Koratkar, J. Phys. Chem. Lett., 2012, 3, 17461753.

32 W. Yuan and G. Shi, J. Mater. Chem. A, 2013, 1, 10078-10091. 33 E. Llobet, Sens. Actuators, B, 2013, 179, 32-45.

34 F. Schedin, A. K. Geim, S. V. Morozov, E. W. Hill, P. Blake, M. I. Katsnelson and K. S. Novoselov, Nat. Mater., 2007, 6, 652-655.

35 J. Patzsch, I. Balog, P. Krauß, C. W. Lehmann and J. J. Schneider, RSC Adv., 2014, 4, 15348.

36 B. Koerbitzer, P. Krauss, C. Nick, S. Yadav, J. J. Schneider and C. Thielemann, 2D Mater., 2016, 3, 24004.

37 R. A. DiLeo, B. J. Landi and R. P. Raffaelle, J. Appl. Phys., 2007, 101, 64307.

38 Y. Wang, S. Serrano and J. J. Santiago-Avilés, Synth. Met., 2003, 138, 423-427.

39 M. S. Dresselhaus, A. Jorio, A. G. Souza Filho and R. Saito, Philos. Trans. R. Soc., A, 2010, 368, 5355-5377.

40 G.-B. Zheng, K. Kouda, H. Sano, Y. Uchiyama, Y.-F. Shi and H.-J. Quan, Carbon, 2004, 42, 635-640. 
41 S. Esconjauregui, C. M. Whelan and K. Maex, Carbon, 2009, 47, 659-669.

42 Y.-H. Zhang, Y.-B. Chen, K.-G. Zhou, C.-H. Liu, J. Zeng, H.-L. Zhang and Y. Peng, Nanotechnology, 2009, 20, 185504.

43 X.-Y. Liu, J.-M. Zhang, K.-W. Xu and V. Ji, Appl. Surf. Sci., 2014, 313, 405-410.

44 O. Monereo, S. Claramunt, G. Vescio, H. Lahlou, R. Leghrib, J. D. Prades, A. Cornet and A. Cirera, in 2013 Transducers \&
Eurosensors XXVII: The 17th International Conference on Solid-State Sensors, Actuators and Microsystems, IEEE, 2013, pp. 1154-1157.

45 J. Jang and J. Bae, Sens. Actuators, B, 2007, 122, 7-13.

46 F. Rigoni, S. Tognolini, P. Borghetti, G. Drera, S. Pagliara, A. Goldoni and L. Sangaletti, Analyst, 2013, 138, 73927399. 